\title{
High prevalence of Y-box protein-1/p18 fragment in plasma of patients with malignancies of different origin
}

Frank Tacke ${ }^{1 \dagger}$, Oliver Galm ${ }^{2 \dagger}$, Nicolas Kanig ${ }^{3 \dagger}$, Eray Yagmur ${ }^{4}$, Sabine Brandt ${ }^{3}$, Jonathan A Lindquist ${ }^{3}$, Christiane S Eberhardt ${ }^{3}$, Ute Raffetseder ${ }^{5}$ and Peter R Mertens ${ }^{3^{*}}$

\begin{abstract}
Background: Expression of the cold shock protein Y-box protein 1 (YB-1) is associated with deleterious outcome in various malignant diseases. Our group recently showed that the detection of an 18 kDa YB-1 fragment (YB-1/p18) in human plasma identifies patients with malignant diseases. We now tested the prevalence, clinical, and diagnostic value of YB-1/p18 detection in common tumors.

Methods: A newly established monoclonal YB-1 antibody was used to detect YB-1/p18 by immunoblotting in plasma samples from 151 unselected tumor patients, alongside established tumor markers and various diagnostic measures, during evaluation for a cancerous disease and in follow-up studies after therapeutic interventions.

Results: Circulating YB-1/p18 was detected in 78\% of patients having a tumor disease. YB-1/p18 positivity was highly prevalent in all examined malignancies, including lung cancer (32/37; 87\%), breast cancer $(7 / 10 ; 70 \%)$, cancer of unknown primary (CUP; 5/5, 100\%) or hematological malignancies (42/62; 68\%). Positivity for YB-1/p18 was independent of other routine laboratory parameters, tumor stage, or histology. In comparison to 13 established tumor markers (cancer antigens 15-3, 19-9, 72-4, and 125; carcinoembryonic antigen; cytokeratin fragments 21-1; neuron-specific enolase; alpha-fetoprotein; beta-2-microglobulin; squamous cell carcinoma antigen; thymidine kinase; tissue polypeptide antigen; pro-gastrin-releasing peptide), YB-1/p18 detection within serum samples was the most sensitive general parameter identifying malignant disorders. YB-1/p18 concentrations altered during therapeutic interventions, but did not predict prognosis.
\end{abstract}

Conclusions: Plasma YB-1/p18 detection has a high specific prevalence in malignancies, thereby providing a novel tool for cancer screening independent of the tumor origin.

Keywords: Cold shock proteins, Cancer disease, Serum biomarker, Cancer screening, Prognosis, YB-1

\section{Background}

Cold shock proteins are evolutionarily conserved, and share a so-called cold shock domain [1,2]. In humans, three members of the protein family have been described, denoted DNA-binding protein A (DbpA) (also called zona occludens 1-associated nucleic acid binding protein (ZONAB) or cold shock domain A (CSDA)), DbpB (Y-box protein-1, YB-1), and DbpC (Contrin). Whereas initial

\footnotetext{
*Correspondence: peter.mertens@med.ovgu.de

${ }^{\dagger}$ Equal contributors

${ }^{3}$ Department of Nephrology and Hypertension, Diabetes and Endocrinology, Otto-von-Guericke University Magdeburg, Leipziger Str. 44, 39120

Magdeburg, Germany

Full list of author information is available at the end of the article
}

studies dealt with the transcriptional activities of cold shock proteins, i.e. their association with the DNA promoter elements of various target genes, it has become clear that cold shock proteins also associate with mRNA and thereby influence the half-life of mRNA as well as affect pre-mRNA splicing [3]. Transcription rates of proliferation-associated genes are upregulated by YB-1, e.g. DNA-polymerase- $\alpha$, epidermal growth-factor receptor, platelet-derived growth factor, and matrix metalloproteinase-2 [1,2]. A pivotal role of YB-1 in cancerogenesis has been proposed by several groups, which has been substantiated by its interplay with c-Myc expression in multiple myeloma, as well as p53 function/signaling in malignant

\section{Biomed Central}

(c) 2014 Tacke et al.; licensee BioMed Central Ltd. This is an open access article distributed under the terms of the Creative Commons Attribution License (http://creativecommons.org/licenses/by/2.0), which permits unrestricted use, distribution, and reproduction in any medium, provided the original work is properly cited. 
melanoma $[4,5]$. YB-1 facilitates the binding of wild type p53 to DNA motifs, however not of mutated p53, and thereby represses cell death-associated fas gene transcription. The first hint for the participation of cold shock proteins in cancerogenesis and the promotion of metastasis formation has been described in breast cancer disease, as YB-1 expression correlates with cell transformation and confers aggressive tumor growth [6,7]. The overexpression of (mostly nuclear) YB-1 has been associated with poor outcome, e.g. early relapses and aggressive tumor growth, in several tumor entities (summarized in [2]). For instance, nuclear YB-1 expression in tumor tissue from patients with non-small cell lung cancer were associated with disease progression, proliferation markers and prognosis [8-10].

Cold shock proteins may also be actively secreted by both transformed and non-transformed cells following challenge with cytokines (e.g. PDGF-B, TGF- $\beta$ ) or exposure to oxidative stress [11]. YB-1 lacks an N-terminal signal peptide motif and therefore its secretion is regulated similar to that of other leaderless proteins, including interleukin-1 $\beta$, high mobility group box protein (HMGB1) and macrophage migratory inhibitory factor (MIF). In addition to the full-length YB-1 protein, we have also detected protein fragments in conditioned cell culture medium [11]. In a recent pilot study, we were able to demonstrate that the detection of YB- $1 / \mathrm{p} 18$ fragment was able to identify patients with malignancies in a well defined cohort of patients with chronic liver diseases awaiting liver transplantation [12]. The band at $18 \mathrm{kDa}$ was identified as the truncated cold-shock domain with peptides corresponding to aa81-137 of the YB-1 protein [12]. In contrast, YB-1/p18 was almost undetectable in human plasma from healthy volunteers, patients with inflammatory diseases, renal, or hepatic failure. We therefore hypothesized that YB-1/p18 detection might represent a novel, yet unrecognized characteristic of patients with malignancies. In order to test this hypothesis, we have conducted the current study in which we tested the prevalence, clinical, and diagnostic value of YB-1/ p18 detection in common tumor entities using a novel immunoblotting system.

\section{Methods}

\section{Patients}

The study protocol was approved by the local ethics committee and conducted in accordance with the ethical standards laid down in the 1974 Declaration of Helsinki (ethics committee of the University Hospital Aachen, RWTH-University, Aachen, Germany, reference number EK 107/05). Written informed consent was obtained from each participant. Plasma samples were obtained from consecutive patients with various malignant disorders presenting to the Outpatient Cancer Clinic at the
University Hospital Aachen, Germany. Only patients with a histologically confirmed diagnosis of a malignancy were included. Concomitant diseases, routine laboratory tests, tumor staging, and current treatment as well as treatment history were recorded. Blood samples were collected in EDTA plasma separator tubes, and plasma was stored at $-80^{\circ} \mathrm{C}$. In $42 / 151$ patients, samples were also obtained during follow-up visits (median 3 samples from different time-points). All patients were followed for at least 12 months after inclusion in the study to assess the predictive value of $\mathrm{YB}-1 / \mathrm{p} 18$ and other tumor markers on survival.

\section{YB-1 immunoblotting}

Human plasma $\left(0.5 \mu \mathrm{l}\right.$ diluted $1: 10$ with $\left.\mathrm{dd}_{2} \mathrm{O}\right)$ was separated on $12.5 \%$ SDS-polyacrylamide gels and transferred to nitrocellulose membranes. Following blocking for $1 \mathrm{~h}$ with $2.5 \%$ milk in Tris-buffered saline the membranes were incubated with primary antibody, monoclonal anti-YB-1 ([13], Portugal (II 2C-5)/ Biotin $1.3 \mathrm{~g} / \mathrm{ml}$ Lot 1 A1 biotinylated, 1:1000) overnight at $4^{\circ} \mathrm{C}$. After extensive washing with TBST, peroxidase-conjugated Streptavidin (Dianova, 1:10,000) was incubated for $1 \mathrm{~h}$ at room temperature. Detection was performed with the ECL system (Amersham).

On each blot, one sample obtained from a patient with metastasized small cell lung cancer that was strongly YB-1/p18 positive was run in parallel as a positive control (Figure 1). The immunoblots were performed and analyzed by a scientist blinded to the origin of the samples. YB-1/ p18 signals were quantified by densitometry (NIH imager)

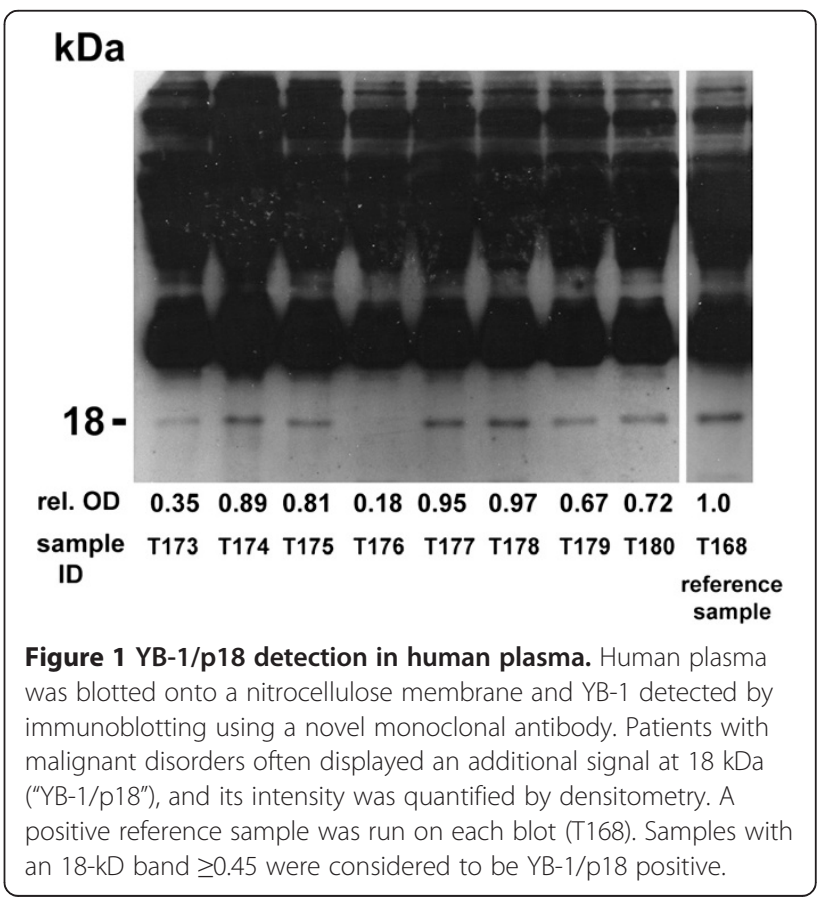


and compared to the positive control, which was assigned the optical density of ' 1.0 '. The relative optical density of the samples was calculated and signals $\geq 0.45$ were considered to be $\mathrm{YB}-1 / \mathrm{p} 18$ positive (Figure 1 ), as previously described [12].

\section{Other tumor markers}

Established tumor markers were assessed using the manufacturers' protocols with reference cut-off values recommended by the manufacturer and validated with internal controls at the Department of Clinical Chemistry and Pathobiochemistry, University Hospital Aachen, Germany. The following assays were used: from Roche, Mannheim, Germany: cancer antigen 125 (CA 125, reference <36 kU/L); carcinoembryonic antigen (CEA, <5 $\mu \mathrm{g} / \mathrm{L} ; \mathrm{CA} 15-3,<26$ kU/L; CA 19-9, <38 kU/L; CA 72-4, <7 kU/L; cytokeratin fragments 21-1 (CYFRA 21-1, <3.4 $\mu \mathrm{g} / \mathrm{L}$; neuron-specific enolase (NSE), <14 $\mu \mathrm{g} / \mathrm{L}$; alpha-fetoprotein (AFP), $<10 \mu \mathrm{g} / \mathrm{L}$; Dade Behring, Marburg, Germany: beta-2-microglobulin (ß2-micro), <1.8 mg/L; Abbott, Wiesbaden, Germany: squamous cell carcinoma antigen (SCC), <1.6 $\mathrm{g} / \mathrm{L}$; DiaSorin S. p.A., Saluggia, Italy: thymidine kinase (TK), <6.8 U/L, tissue polypeptide antigen (TPA), <92 U/L; IBL, Hamburg, Germany: pro-gastrin-releasing peptide (PGRP), $<46 \mathrm{ng} / \mathrm{L}$. Due to limited sample availability, these tumor markers were detected in subgroups of the whole cohort.

\section{Statistics}

Results were reported as median and range, and differences between groups were assessed by Mann-Whitney U-test, Kruskal-Wallis-ANOVA, or chi-square-test [14]. The prognostic value of the variables was tested by univariate and multivariate analyses in the Cox regression model. Kaplan Meier curves were plotted to display the impact on survival [15]. The manufacturers' reference intervals for other tumor markers were used as the cut-offs discriminating tumor marker positivity and negativity, respectively. All statistical analyses were performed using SPSS.

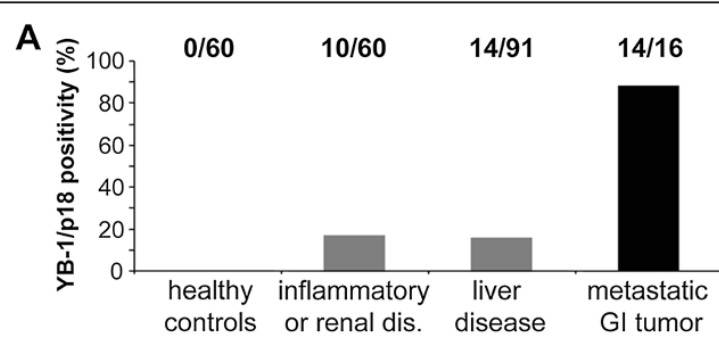

B
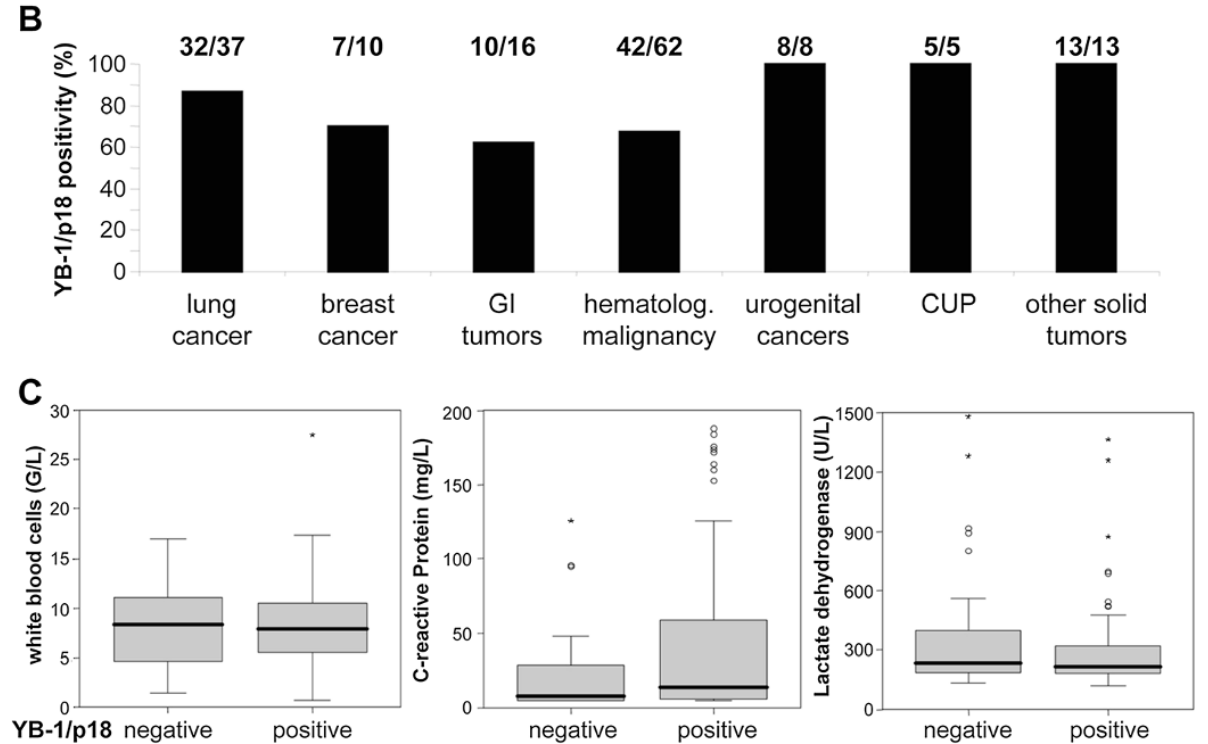

Figure 2 High prevalence of circulating YB-1/p18 in patients with various malignancies. (A) YB-1/p18 was previously measured in healthy volunteers $(n=60)$, patients with inflammatory or renal disease $(n=60)$, and patients with chronic liver disease $(n=91)$ with a low rate of YB-1/ p18 positivity in patients without malignancies. In contrast, almost all patients with metastatic gastrointestinal tumors $(n=16)$ tested YB-1/p18 positive. (B) YB-1/p18 was detected in plasma samples of patients with malignant diseases with a rate of $62.5 \%$ (gastrointestinal [GI] tumors) to 100\%. CUP, cancer of unknown primary site. (C) Cancer patients with or without detection of plasma YB-1/p18 did not differ with respect to their white-blood cell count (WBC), C-reactive protein (CRP) or lactate dehydrogenase (LDH); P > 0.05, not significant, U-Test. The box-and-whiskers plots display the median, quartiles, range and extreme values. The whiskers extend from the minimum to the maximum value excluding outside (>1.5 times upper/lower quartile, open circle) and "far out" (>3 time upper/lower quartile, asterisks) values. 


\section{Results}

Circulating YB-1/p18 is frequently detected in various malignant diseases

Our group has recently shown that a YB-1/p18 fragment, detected by immunoblotting with a novel biotinylated monoclonal antibody (Figure 1), can be found in the plasma of patients with malignancies. In a prior study from our group, none of the healthy volunteers $(0 / 60)$ tested positive for $\mathrm{YB}-1 / \mathrm{p} 18$, whereas $88 \%$ of patients with metastatic gastrointestinal tumors (14/16) had detectable plasma YB-1/p18 levels (Figure 2A) [12]. In two cohorts of patients without overt malignancies, but with inflammatory or renal diseases, as well as patients with chronic liver disease, YB-1/p18 positivity was detected in approximately $15 \%$ of cases (Figure 2A) [12]. In order to assess the prevalence of YB-1/p18 in malignant diseases, 151 patients (56\% male, $44 \%$ female, median age 65 years, range 19-84 years) with various malignancies were included in this study (Table 1 ). The different etiologies of the malignancies are given in Table 1, the stage of remission, tumor staging, and current therapy are listed in Table 2. YB-1/p18 was detected in plasma samples of $77.5 \%(117 / 151)$ of all patients. There was no difference between male (79.8\% positive) and female $(74.6 \%)$ patients $(P>0.05$, not significant, Chi-square test, Table 3). Furthermore, the patient's age had no influence on YB-1/p18 positivity either (not shown).

Among the different etiologies, the vast majority of tested patients with lung cancer $(32 / 37,86.5 \%)$, breast cancer $(7 / 10,70 \%)$, urogenital tumors $(8 / 8,100 \%)$, cancer of unknown primary site $(5 / 5,100 \%)$, and other solid tumors $(13 / 13,100 \%)$ had detectable plasma YB-1/p18 levels (Figure 2B). Patients with gastrointestinal tumors $(10 / 16,62.5 \%)$ and hematological malignancies $(42 / 62$, $67.7 \%)$ had a lower prevalence of plasma YB-1/p18 levels above the defined threshold. Within the group of patients with hematological malignancies (Table 3), lymphoma $(21 / 25,84 \%)$ or multiple myeloma $(10 / 13,77 \%)$ were more often associated with plasma YB-1/p18 than acute or chronic leukemia $(5 / 9,56 \%)$ or myelodyplastic disorders $(2 / 10,20 \%)$. In contrast, in patients with lung cancer, urogenital carcinomas, or other solid tumors, the histological subtypes did not differ with respect to the YB-1/ p18 result (Table 3).

We also analyzed if patients with or without detectable plasma YB-1/p18 levels varied in their laboratory or other clinical characteristics. As shown in Figure $2 \mathrm{C}$, parameters indicating inflammation or (general) tumor load, such as white blood cell count (WBC, median $7.9 \mathrm{G} / \mathrm{L}$ in positive vs. 8.3 in negative patients), C-reactive protein (CRP, median 14 versus $8 \mathrm{mg} / \mathrm{L}$ ), or lactate dehydrogenase (LDH, median 216 versus 234 U/L) did not significantly differ between YB-1/p18 positive and negative patients $(\mathrm{P}>0.05$, U-test). Furthermore, parameters associated with liver or renal function deterioration did not display significant
Table 1 Patient characteristics and tumor entities

\begin{tabular}{|c|c|c|c|c|}
\hline & \multirow[b]{2}{*}{$\mathbf{n}$} & \multirow[b]{2}{*}{$\%$} & \multicolumn{2}{|c|}{ Age [years] } \\
\hline & & & Median & Range \\
\hline All patients & 151 & 100 & 64.8 & $18.5-84.4$ \\
\hline Male & 84 & 55.6 & & \\
\hline Female & 67 & 44.4 & & \\
\hline \multicolumn{5}{|l|}{ Malignancy } \\
\hline Group I: lung cancer & 37 & 24.5 & 62.8 & 43.9- 83.5 \\
\hline Adeno & 15 & 9.9 & & \\
\hline Small cell & 10 & 6.6 & & \\
\hline Squamous & 10 & 6.6 & & \\
\hline Other non small cell & 2 & 1.3 & & \\
\hline Group II: breast cancer & 10 & 6.6 & 55.9 & 34.9- 71.3 \\
\hline Ductal & 9 & 90 & & \\
\hline Lobular & 1 & 10 & & \\
\hline Group III: gastrointestinal & 16 & 10.6 & 67.5 & $42.3-84.4$ \\
\hline Stomach cancer & 3 & 2.0 & & \\
\hline Colorectal cancer & 7 & 4.6 & & \\
\hline Other & 6 & 4.0 & & \\
\hline Group IV: hematological & 62 & 41.1 & 64.2 & $18.5-83.2$ \\
\hline Acute myeloid leukemia & 7 & 4.6 & & \\
\hline Chronic myelogenous leukemia & 2 & 1.3 & & \\
\hline Hodgkin's lymphoma & 5 & 3.3 & & \\
\hline Non-Hodgkin's lymphoma & 13 & 8.6 & & \\
\hline Other lymphoma & 7 & 4.6 & & \\
\hline Multiple myeloma & 13 & 8.6 & & \\
\hline Idiopathic thrombocytopenia & 5 & 3.3 & & \\
\hline Myelodysplastic syndrome & 10 & 6.6 & & \\
\hline Group V: urogenital cancers & 8 & 5.3 & 64.4 & 38.4- 81.7 \\
\hline Ovarian cancer & 2 & 1.3 & & \\
\hline Testicular cancer & 2 & 1.3 & & \\
\hline Prostate cancer & 1 & 0.7 & & \\
\hline Urinary tract cancer & 3 & 2.0 & & \\
\hline Group VI: CUP & 5 & 3.3 & 64.7 & $41.2-80.6$ \\
\hline Group VII: other solid tumors & 13 & 8.6 & 64.1 & $30.7-73.5$ \\
\hline
\end{tabular}

differences either (data not shown). There was no difference in tumor stage, metastases, or co-morbidities (such as chronic heart failure, arterial hypertension, coronary artery disease, chronic obstructive pulmonary disease, diabetes, renal insufficiency, etc.) between YB-1/p18 seropositive and -negative patients in the total cohort.

\section{YB-1/p18 is a more sensitive diagnostic biomarker for cancer than established tumor markers}

A panel of 13 established tumor markers was assessed alongside $\mathrm{YB}-1 / \mathrm{p} 18$ in the cohort of patients with malignancies, namely CA 125, CEA, CA 15-3, CA 19-9, CA 
Table 2 Stage of remission, therapy and metastases at study entry

\begin{tabular}{|c|c|c|c|c|c|c|c|c|}
\hline & n (\%) & $\begin{array}{l}\text { Group I: } \\
\text { lung cancer } \\
\text { n (\%) }\end{array}$ & $\begin{array}{c}\text { Group II: } \\
\text { breast cancer } \\
\text { n (\%) }\end{array}$ & $\begin{array}{c}\text { Group III: } \\
\text { GI tumors } \\
\text { n (\%) }\end{array}$ & $\begin{array}{c}\text { Group IV: } \\
\text { hematol. } \\
\text { n (\%) }\end{array}$ & $\begin{array}{c}\text { Group V: } \\
\text { uro-genital } \\
\text { n (\%) }\end{array}$ & n (\%) & $\begin{array}{c}\text { Group VII: } \\
\text { others } \\
\text { n (\%) }\end{array}$ \\
\hline \multicolumn{9}{|c|}{ Stage of remission } \\
\hline ID & 99 (65.6) & $27(27.3)$ & $1(1.1)$ & $9(9.1)$ & $45(45.5)$ & $5(5)$ & $5(5)$ & $7(7)$ \\
\hline$C R$ & $2(1.3)$ & 0 & 0 & 0 & $2(100)$ & 0 & 0 & 0 \\
\hline$P R$ & $4(2.6)$ & $1(25)$ & 0 & 0 & $2(50)$ & $1(25)$ & 0 & 0 \\
\hline NC & $2(1.3)$ & $1(50)$ & 0 & 0 & $1(50)$ & 0 & 0 & 0 \\
\hline PD & $44(29.1)$ & $8(18.2)$ & $9(20.5)$ & $7(15.9)$ & $12(27.3)$ & $2(4.5)$ & 0 & $6(13.6)$ \\
\hline \multicolumn{9}{|l|}{ Metastases } \\
\hline CNS & 16 (10.6) & $8(50)$ & 0 & $1(6.3)$ & $3(18.7)$ & $2(12.5)$ & 0 & $2(12.5)$ \\
\hline Bone & $32(21.2)$ & $9(45)$ & $6(18.8)$ & $1(3.1)$ & $8(25)$ & $3(9.4)$ & $2(6.3)$ & $3(9.4)$ \\
\hline Liver & $17(11.3)$ & $2(11.8)$ & $2(11.8)$ & $8(47.0)$ & $3(17.6)$ & $2(11.8)$ & 0 & 0 \\
\hline Lymphatic & $85(56.3)$ & $21(24.1)$ & $7(8)$ & $11(12.6)$ & $33(37.9)$ & $5(5.7)$ & $3(3.4)$ & $5(5.7)$ \\
\hline \multicolumn{9}{|c|}{ Therapy (at study entry) } \\
\hline Chemo & $18(11.9)$ & $4(22.2)$ & $1(5.6)$ & $1(5.6)$ & $4(22.2)$ & $2(11.1)$ & $1(5.6)$ & $5(27.7)$ \\
\hline Radiation & $3(2)$ & $2(66.7)$ & 0 & 0 & 0 & 0 & 0 & $1(33.3)$ \\
\hline Hormone & $3(2)$ & 0 & $1(33.3)$ & 0 & $2(66.7)$ & 0 & 0 & 0 \\
\hline
\end{tabular}

ID, initial diagnosis; $C R$, complete remission; PR, partial remission; NC, no change; PD, progressive disease.

72-4, CYFRA 21-1, NSE, AFP, $\beta 2$-microglobulin, SCC, thymidine kinase, TPA, and PGRP. YB-1/p18-positivity was not statistically linked to positivity of any of these parameters (cross-table analysis and Chi-square-tests, data not shown). For the total cohort, YB-1/p18 was the marker with the highest sensitivity in detecting malignancies (78\% positive, Figure 3A). CA 125 (59\%) and $\beta 2$-microglobulin (74\%) also tested positive in the majority of cancer patients, whereas all other markers remained negative in at least half of the patient cohort (Figure 3A).

When the different tumor entities were analyzed separately, YB-1/p18 positivity was the most frequently detected tumor marker in patients with lung cancer (Figure 3B), urogenital tumors, CUP syndrome, breast cancer (Figure 3C), and the mixed group of patients with other solid tumors (Figure 3D, $\mathrm{n}=13$ ) that included very heterogeneous entities such as tumors of the CNS $(n=3)$, nasopharyngeal tumors $(n=3)$, or sarcomas $(n=2)$. Figure $3 B$ and $D$ display the next most sensitive tumor markers for these subgroups, emphasizing that none of the other markers had a similar overall sensitivity comparable to YB-1/p18. In most cases, such as in lung cancer, YB-1/p18 positivity was independent of the histological subtype (Figure 4).

Importantly, some tumor markers had a higher sensitivity than YB-1/p18 in distinct subgroups of patients. For instance, CA 15-3 was more sensitive, while NSE or TPA tested equally sensitive in patients with breast cancer when compared to YB-1/p18 (Figure 3C). In a prior study, we had reported AFP to be more sensitive in detecting hepatocellular carcinoma than YB-1/p18 [12].
YB-1/p18 detection in plasma varies during therapy, but has limited potential to predict prognosis

One important clinical value of established tumor markers is their correlation in individual patients with the effectiveness of treatment. In our cohort, we followed 42 out of the 151 patients during the course of therapy. As shown in Figure 5 for an individual patient with small cell lung cancer subsequent to chemotherapy, YB-1/p18 detection in plasma was altered, indicating a response to therapy. Concentrations of other tumor markers that were found positive were also lower after response to therapy. However, truly quantitative assessments of tumor markers were superior to measurement of $\mathrm{YB}-1 / \mathrm{p} 18$ intensity in immunoblotting for predicting individual response to cancer therapy (data not shown).

Based on the association with histological expression of YB-1 by tumor tissue and unfavorable prognosis (summarized in [2]) we tested whether positivity for YB-1/p18 in serum or other tumor markers were associated with survival. Using Cox regression analysis, YB-1/p18 seropositivity did not predict survival; similar to most other tumor markers (Figure 6). Only positivity for CA $72-4$ and TPA was associated with poor prognosis within the cohort of tumor patients, indicating that the tumor markers that were specifically found in subtypes of cancers had a higher probability to have additional prognostic value.

\section{Discussion}

In this study, we set out to test the prevalence and relevance of YB-1/p18 seropositivity in patients diagnosed 
Table 3 Positivity for YB-1/p18 detection in human serum samples of patients with different malignant disorders

\begin{tabular}{|c|c|c|}
\hline & $\mathrm{n}$ & YB-1/p18 positivity n/N (\%) \\
\hline All patients & 151 & $117 / 151(77.5)$ \\
\hline Male & 84 & $67 / 84(79.8)$ \\
\hline Female & 67 & $50 / 67(74.6)$ \\
\hline \multicolumn{3}{|l|}{ Malignancy } \\
\hline Group I: lung cancer & 37 & $32 / 37(86.5)$ \\
\hline Adeno & 15 & $12 / 15(80)$ \\
\hline Small cell & 10 & $9 / 10(90)$ \\
\hline Squamous & 10 & $9 / 10(90)$ \\
\hline Non small cell & 2 & $2 / 2(100)$ \\
\hline Group II: breast cancer & 10 & $7 / 10(70)$ \\
\hline Ductal & 9 & $6 / 9(66.7)$ \\
\hline Lobular & 1 & $1 / 1(100)$ \\
\hline Group III: gastrointestinal & 16 & $10 / 16(62.5)$ \\
\hline Stomach cancer & 3 & $2 / 3(66.7)$ \\
\hline Colorectal cancer & 7 & 4/7 (57.1) \\
\hline Other & 6 & $4 / 6(66.7)$ \\
\hline Group IV: hematological & 62 & $42 / 62(67.7)$ \\
\hline Acute myeloid leukemia & 7 & 4/7 (57.1) \\
\hline Chronic myelogenous leukemia & 2 & $1 / 2(50)$ \\
\hline Hodgkin's lymphoma & 5 & $4 / 5(85.7)$ \\
\hline Non-Hodgkin's lymphoma & 13 & $11 / 13(84.6)$ \\
\hline Other lymphoma & 7 & 6/7 (85.7) \\
\hline Multiple myeloma & 13 & 10/13 (77) \\
\hline Idiopathic thrombocytopenia & 5 & $4 / 5(76.9)$ \\
\hline Myelodysplastic syndrome & 10 & $2 / 10(20)$ \\
\hline Group V: urogenital cancers & 8 & $8 / 8(100)$ \\
\hline Ovarian cancer & 2 & $2 / 2(100)$ \\
\hline Testicular cancer & 2 & $2 / 2(100)$ \\
\hline Prostate cancer & 1 & $1 / 1(100)$ \\
\hline Urinary tract cancer & 3 & $3 / 3(100)$ \\
\hline Group VI: CUP & 5 & $5 / 5(100)$ \\
\hline Group VII: other solid tumors & 13 & $13 / 13(100)$ \\
\hline
\end{tabular}

with different cancerous and leukemic/hematological diseases. Our study cohort was comprised of an unselected heterogeneous group of patients with malignant diseases of various entities and at various stages of disease (e.g., early and advanced, before or during chemotherapy etc.). The main finding of the study is a high positivity rate of the YB-1/p18 in plasma samples of cancer patients. Unexpectedly, this positivity is found irrespective of the underlying cancer provenience and other clinical co-variables that were tested. Such an universal positivity is difficult to understand, given that most cancers derive from specific genetic or epigenetic defects with ensuing alterations of the cellular genome and cancer cell environment [16]. For all the other tested tumor markers, the sensitivity and specificity rates were lower.

The finding of universal seropositivity for circulating YB-1/p18 fragments may be explained by similar widespread YB-1 positivity in tissue samples of cancer patients $[2,4,17]$, emphasizing that YB-1 dysregulation is a common feature found in tumor tissue. So far, immunostaining and analysis of the subcellular distribution of YB-1 from tumor tissue has been used to correlate and predict poor prognosis, especially with nuclear protein accumulation in breast cancer patients [2]. Our findings of circulating YB-1/p18 fragments in plasma of patients with cancer now indicates that dysregulated YB-1 may be prone to be released as fragments into the circulation, which would allow its easy use as a non-invasive disease marker. Similar observations are currently gathered for many micro-RNA (miRNA) in cancerous diseases, as the dysregulation of distinct key miRNA in tumor tissue can be associated with elevated levels of circulating miRNAs in cancer patients [18]. Nevertheless, the profile of circulating miRNAs appears very specific for different types of malignancies or non-malignant diseases [19], while YB-1/p18 detection did not allow us to distinguish between different tumor entities.

It is important to emphasize that YB-1/p18 detection appeared relatively specific for malignant diseases and had a high sensitivity in various malignancies, but its detection, unlike many established tumor markers, was not clearly related to the disease stage or prognosis. The reason for this might be the semi-quantitative nature of our immunoblotting assay. The threshold for YB-1/ p18 seropositivity was optimized for sensitivity [12], and immunoblotting quantification against a positive control certainly did not allow linear-range quantification. In fact, in individual patients with several longitudinal YB-1/p18 measurements, there was a moderate association between the quantification of the signal with the response or failure to therapy. Due to the relatively small number of patients with distinct hematological malignancies and the semiquantitative nature of the immunoblotting method, we were unable to detect a clear association between the number of circulating blasts and the intensity of p18 bands. Thus, a different, more quantitative technique for YB-1/p18 fragment measurement is highly warranted to better estimate the prognostic value of $\mathrm{YB}-1 / \mathrm{p} 18$ in cancerous disease. The development of such an ELISA system, however, is hampered by the fact that currently most antibodies detect not only the p18 fragment, but also full-length YB-1 [13].

It is currently unclear, whether circulating YB-1/p18 fragments are functionally active in patients with malignancies. Inside tumor cells, YB-1 has been shown to fulfill 


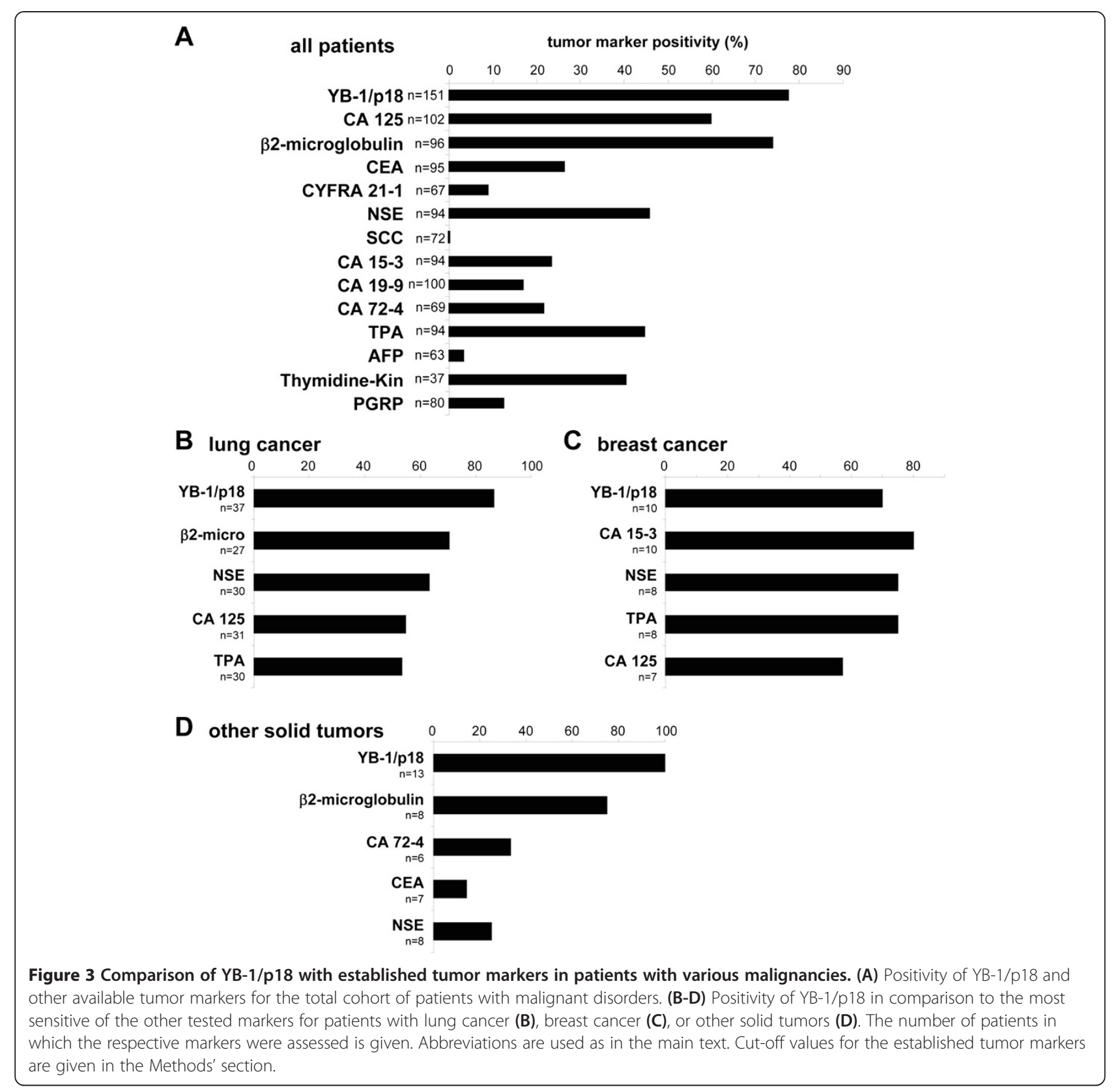

critical cellular functions, such as the transcriptional upregulation of proliferation-associated and downregulation of apoptosis-related genes or induction of drug-transporter genes (like MDR-1) involved in chemoresistance $[6,20]$. Data from our own laboratories indicated that also extracellular YB-1 may be involved in tumor progression, since adding recombinant $\mathrm{YB}-1$ protein to cancer cell-lines in vitro revealed profound pro-mitogenic effects suggesting that secreted YB-1 or its fragments could act as a tumor growth-promoting factor [11]. Further studies are needed to define the exact functions of circulating full-length YB-1 compared to p18 fragments and to define the exact cellular source (tumor vs. stromal cells) of $\mathrm{YB}-1 / \mathrm{p} 18$ in patients with malignant disorders.

Nevertheless, our study demonstrated that circulating YB-1/p18 is highly prevalent in cancer patients and reasonably specific in distinguishing malignant versus non-malignant disorders. One of the challenges in the era of 'personalized medicine' is the early detection of cancer, and many biomarkers have failed to be used for screening purposes in clinical practice, even for the most common tumor entities, such as breast or lung cancer [21]. The data provided by our study suggest that it might be highly valuable to incorporate YB-1/ p18 measurement into cancer screening approaches. 

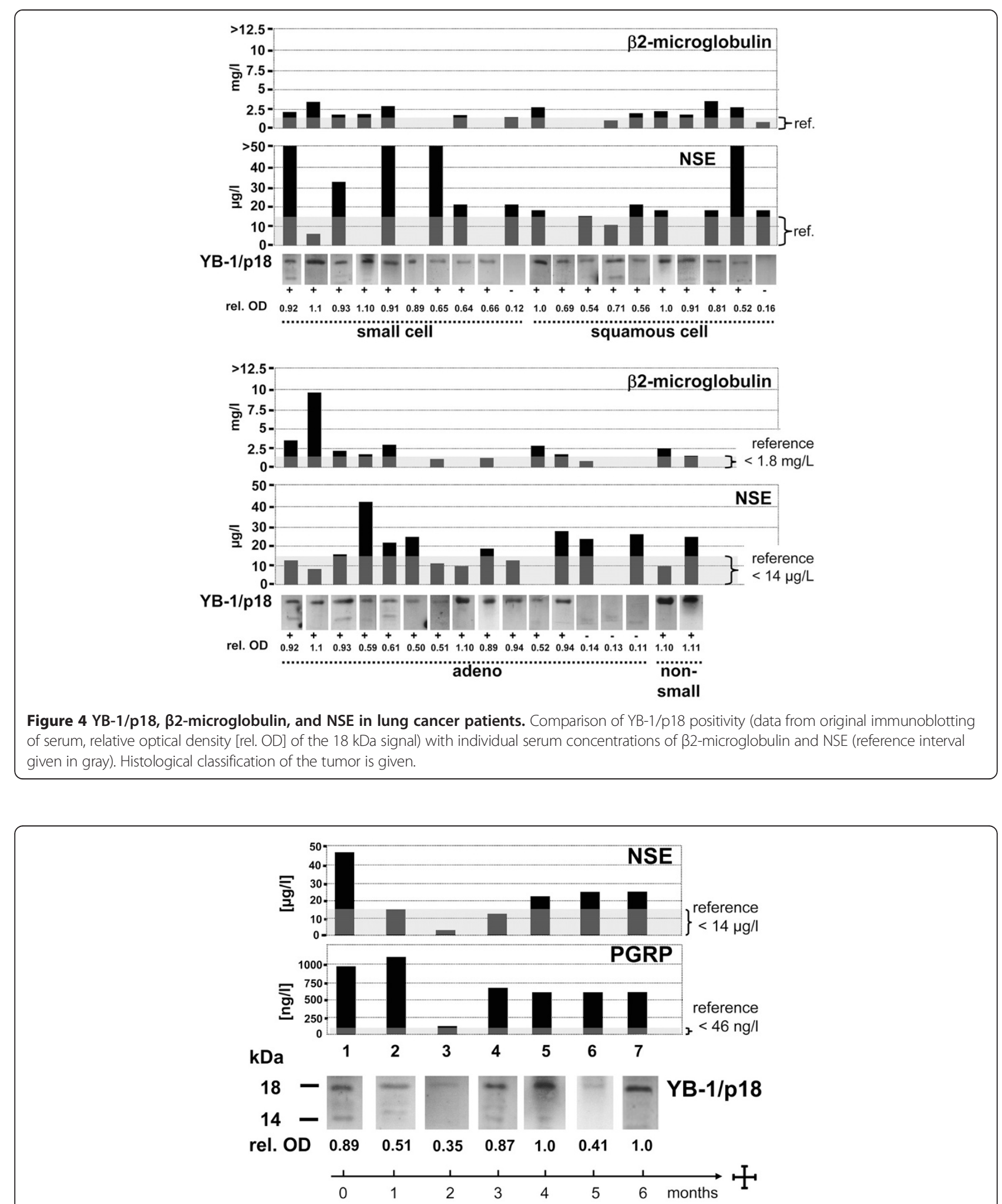

Figure 5 YB-1/p18 during therapy in a patient with small cell lung cancer. Serum samples were obtained from a 45-year old male with small cell lung cancer at diagnosis (lane 1) and during chemotherapy with cisplatin/etoposide (lanes 2-3), initially with good response. He was found to progress in month 3 (lane 4), and then was treated with epirubicine, cyclophosphamide, and vincristine (lanes 5-7). Simultaneous measurements of NSE and PGRP are displayed. NSE and PGRP were the only two positive parameters of 13 tumor markers initially tested in this patient. The relative optical density (rel. OD) of the YB-1/p18 signal in immunoblotting is given. 

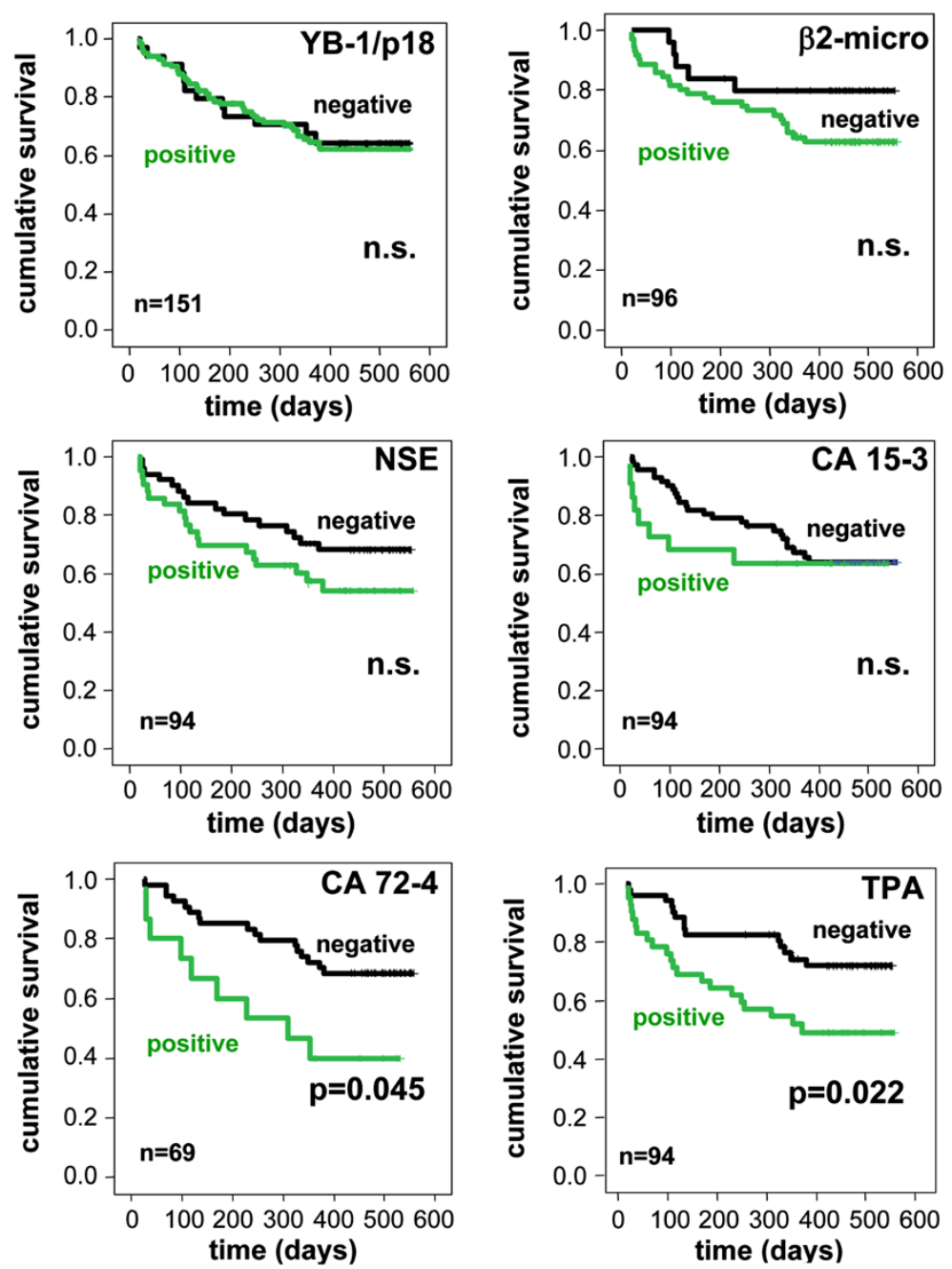

Figure 6 Prognostic value of YB-1/p18 positivity in comparison to established tumor markers. Kaplan-Meier curves are depicted to display survival in patients with positive or negative tumor markers, p-values from Cox regression analyses are given; n.s., not significant. The number of patients in which the respective tumor marker has been assessed is given in the figure. Except for CA 72-4 and TPA, that had predictive value for patients' survival, tumor markers were not related to the prognosis.

However, it is important to point out that our study comprised a heterogeneous group of patients with different tumor entities and stages. Due to the relatively small patient numbers in the subgroups, our study does not allow to draw specific conclusions for individual tumor entities, e.g. on associations with staging, prognosis or treatment response. Prospective trials with large cohorts are warranted to confirm that circulating YB-1/ p18 fragments might be suitable as a general biomarker for the presence of malignant disorders and to assess its potential specific value in distinct tumor entities as a prognostic marker.

\section{Conclusions}

The detection of cold shock proteins, especially of YB-1, by immunostaining in tumor tissue of cancer patients has been related to adverse outcome. Our study now demonstrated that a $18 \mathrm{kD}$ secreted form of YB1 , termed $\mathrm{YB}-1 / \mathrm{p} 18$, carries potential as a circulating biomarker in oncology. By using a novel immunoblotting assay for $\mathrm{YB}-1 / \mathrm{p} 18$ for analyzing $\mathrm{YB}-1 / \mathrm{p} 18$ in plasma of 151 unselected patients with various malignancies, circulating YB-1/p18 had a higher prevalence compared to other established tumor markers and was associated to therapy response in longitudinal assessments. Unlike 'traditional' entity-specific cancer biomarkers, YB-1/p18 was largely independent from the histological subtype or stage of disease progression and did not predict the individual prognosis. These data indicate that YB-1/p18 fragments in human plasma may therefore have exceptional potential as a cancer screening marker. 


\section{Abbreviations}

AFP: Alpha-fetoprotein; 32 -micro: Beta-2-microglobulin; CA 125: Cancer antigen 125; CA19-9: Carbohydrate antigen; CEA: Carcinoembryonic antigen; CRP: C-reactive protein; CSD: Cold shock domain; CYFRA 21-1: Cytokeratin fragments 21-1; CUP: Cancer of unknown primary; Dbp: DNA-binding protein; HMGB: High mobility group box protein; LDH: Lactate dehydrogenase; MDR: Multiple drug resistence; miRNA: micro-RNA; NSE: Neuron-specific enolase; PGRP: Pro-gastrin-releasing peptide; PSA: Prostate-specific antigen; ROC: Receiver operating characteristic; SCC: Squamous cell carcinoma antigen; TGF: Transforming growth factor; TK: Thymidine kinase; TPA: Tissue polypeptide antigen; WBC: White blood cell count; YB-1: Y-box protein-1; YB-1/p18: YB-1 protein fragment p18.

\section{Competing interests}

None of the authors declares competing financial or non-financial interests.

\section{Authors' contributions}

NK and CSE conducted YB-1 immunoblots. NK, OG and EY performed patient recruitment and provided samples. SB, JAL and UR provided experimental tools and assisted in experiments. FT, NK and PRM designed the study, analyzed data and wrote the manuscript. All authors read and approved the final manuscript.

\section{Acknowledgments}

The study has been funded by Sonderforschungsbereiche (SFB) 854 and TRR57, German Research Foundation (DFG ME1365/7-1 to PRM, Ta 434/2-1 to FT), Fritz Bender Stiftung (to UR) and the Interdisciplinary Centre for Clinical Research (IZKF) within the Faculty of Medicine at the RWTH Aachen University (to FT).

\section{Author details}

${ }^{1}$ Medical Clinic III, University Hospital RWTH-Aachen, Pauwelsstrasse 30, 52074 Aachen, Germany. ${ }^{2}$ Medical Clinic IV, University Hospital RWTH-Aachen, Pauwelsstrasse 30, 52074 Aachen, Germany. ${ }^{3}$ Department of Nephrology and Hypertension, Diabetes and Endocrinology, Otto-von-Guericke University Magdeburg, Leipziger Str. 44, 39120 Magdeburg, Germany. ${ }^{4}$ Medical Care Center, Dr. Stein and colleagues, 41061 Mönchengladbach, Germany. ${ }^{5}$ Medical Clinic II, University Hospital RWTH-Aachen, Pauwelsstrasse 30, 52074 Aachen, Germany.

Received: 25 March 2013 Accepted: 31 October 2013

Published: 20 January 2014

\section{References}

1. Brandt S, Raffetseder U, Djudjaj S, Schreiter A, Kadereit B, Michele M, Pabst M, Zhu C, Mertens PR: Cold shock Y-box protein-1 participates in signaling circuits with auto-regulatory activities. Eur J Cell Biol 2011, 91(6-7):464-471.

2. Lasham A, Print CG, Woolley AG, Dunn SE, Braithwaite AW: YB-1: oncoprotein, prognostic marker and therapeutic target? Biochem J 2013, 449(1):11-23.

3. Raffetseder U, Frye B, Rauen $T$, Jurchott $K$, Royer HD, Jansen PL, Mertens PR: Splicing factor SRp30c interaction with Y-box protein-1 confers nuclear YB-1 shuttling and alternative splice site selection. J Biol Chem 2003, 278 (20):18241-18248.

4. Bommert KS, Effenberger M, Leich E, Kuspert M, Murphy D, Langer C, Moll R, Janz S, Mottok A, Weissbach S, et al: The feed-forward loop between YB-1 and MYC is essential for multiple myeloma cell survival. Leukemia 2012, 27(2):441-450

5. Sinnberg T, Sauer B, Holm P, Spangler B, Kuphal S, Bosserhoff A, Schittek B: MAPK and PI3K/AKT mediated YB-1 activation promotes melanoma cell proliferation which is counteracted by an autoregulatory loop. Exp Dermatol 2012, 21(4):265-270.

6. Bargou RC, Jurchott K, Wagener C, Bergmann S, Metzner S, Bommert K, Mapara MY, Winzer KJ, Dietel M, Dorken B, et al: Nuclear localization and increased levels of transcription factor YB-1 in primary human breast cancers are associated with intrinsic MDR1 gene expression. Nat Med 1997, 3(4):447-450

7. Bergmann S, Royer-Pokora B, Fietze E, Jurchott K, Hildebrandt B, Trost D, Leenders F, Claude JC, Theuring F, Bargou R, et al: YB-1 provokes breast cancer through the induction of chromosomal instability that emerges from mitotic failure and centrosome amplification. Cancer Res 2005, 65(10):4078-4087.
8. Hyogotani A, Ito K, Yoshida K, Izumi H, Kohno K, Amano J: Association of nuclear YB-1 localization with lung resistance-related protein and epidermal growth factor receptor expression in lung cancer. Clin Lung Cancer 2012, 13(5):375-384

9. Shibahara K, Sugio K, Osaki T, Uchiumi T, Maehara Y, Kohno K, Yasumoto K, Sugimachi K, Kuwano M: Nuclear expression of the Y-box binding protein, YB-1, as a novel marker of disease progression in non-small cell lung cancer. Clin Cancer Res 2001, 7(10):3151-3155.

10. Yoshimatsu T, Uramoto H, Oyama T, Yashima Y, Gu C, Morita M, Sugio K, Kohno K, Yasumoto K: Y-box-binding protein-1 expression is not correlated with p53 expression but with proliferating cell nuclear antigen expression in non-small cell lung cancer. Anticancer Res 2005, 25(5):3437-3443.

11. Frye BC, Halfter S, Djudjaj S, Muehlenberg P, Weber S, Raffetseder U, En-Nia A, Knott H, Baron JM, Dooley S, et al: Y-box protein-1 is actively secreted through a non-classical pathway and acts as an extracellular mitogen. EMBO reports 2009, 10(7):783-789.

12. Tacke F, Kanig N, En-Nia A, Kaehne T, Eberhardt CS, Shpacovitch V, Trautwein C, Mertens PR: Y-box protein-1/p18 fragment identifies malignancies in patients with chronic liver disease. BMC Cancer 2011, 11:185.

13. Dahl E, En-Nia A, Wiesmann F, Krings R, Djudjaj S, Breuer E, Fuchs T, Wild PJ, Hartmann A, Dunn SE, et al: Nuclear detection of Y-box protein-1 (YB-1) closely associates with progesterone receptor negativity and is a strong adverse survival factor in human breast cancer. BMC Cancer 2009, 9:410.

14. Yagmur E, Trautwein C, Gressner AM, Tacke F: Resistin serum levels are associated with insulin resistance, disease severity, clinical complications, and prognosis in patients with chronic liver diseases. Am J Gastroenterol 2006, 101(6):1244-1252.

15. Koch A, Voigt S, Kruschinski C, Sanson E, Duckers H, Horn A, Yagmur E, Zimmermann H, Trautwein C, Tacke F: Circulating soluble urokinase plasminogen activator receptor is stably elevated during the first week of treatment in the intensive care unit and predicts mortality in critically ill patients. Critical care 2011, 15(1):R63.

16. Rizki A, Weaver VM, Lee SY, Rozenberg Gl, Chin K, Myers CA, Bascom JL, Mott JD, Semeiks JR, Grate LR, et al: A human breast cell model of preinvasive to invasive transition. Cancer Res 2008, 68(5):1378-1387.

17. Janz M, Harbeck N, Dettmar P, Berger U, Schmidt A, Jurchott K, Schmitt M, Royer HD: Y-box factor YB-1 predicts drug resistance and patient outcome in breast cancer independent of clinically relevant tumor biologic factors HER2, UPA and PAl-1. Int J Cancer 2002, 97(3):278-282.

18. Mo MH, Chen L, Fu Y, Wang W, Fu SW: Cell-free circulating miRNA biomarkers in cancer. J Cancer 2012, 3:432-448.

19. Roderburg C, Mollnow T, Bongaerts B, Elfimova N, Vargas Cardenas D, Berger K, Zimmermann H, Koch A, Vucur M, Luedde M, et al: Micro-RNA profiling in human serum reveals compartment-specific roles of miR-571 and miR-652 in liver cirrhosis. PloS one 2012, 7(3):e32999.

20. Oda Y, Ohishi Y, Saito T, Hinoshita E, Uchiumi T, Kinukawa N, Iwamoto Y, Kohno K, Kuwano M, Tsuneyoshi M: Nuclear expression of Y-box-binding protein-1 correlates with P-glycoprotein and topoisomerase II alpha expression, and with poor prognosis in synovial sarcoma. J Pathol 2003, 199(2):251-258.

21. Schmalfuss F, Kolominsky-Rabas PL: Personalized medicine in screening for malignant disease: a review of methods and applications. Biomarker Insights 2013, 8:9-14

doi:10.1186/1471-2407-14-33

Cite this article as: Tacke et al.: High prevalence of $\mathrm{Y}$-box protein-1/p18 fragment in plasma of patients with malignancies of different origin. BMC Cancer 2014 14:33. 